\title{
The Sero-Prevalence of Cytomegalovirus Infection among Women with Abortion and Intrauterine Death in Erbil City Kurdistan Region , Iraq
}

Katan Sabir Ali $(\mathrm{PhD})^{1}$

Abstract

Background: Cytomegalovirus (CMV) is a major causative agent of prenatal and perinatal infections and may lead to important complications on pregnancy.

Objective: To find out the sero-prevalence of CMV $\operatorname{IgM}$ and $\mathrm{IgG}$ and its association with the history of abortion and / or intra-uterine death, as well as, to study the association between the mentioned prevalence with some socio-demographic variables.

Patients and Methods: A case-control study was performed during the period between October 2018 to April 2019 in Erbil city (Kurdistan region, Iraq) on 75 pregnant women with history of abortion and / or intra-uterine death; and 75 healthy women with normal pregnancy who served as a control group. The women had been referred to the central laboratory department of the Maternity Teaching Hospital for the detection and evaluation of sero-prevalence of CMV specific IgM and IgG markers. The study was approved by the Ethics Committee of Health Sciences College, Hawler Medical University and informed consent was obtained from the patients and controls.

Results: The sero-prevalence of CMV-specific IgG was $100 \%$ in each of the study groups. The sero- prevalence of CMV-specific IgM was $8 \%$ among women with abnormal pregnancy, while, none of the women of the control group had a positive IgM. No significant association was detected between CMV-specific IgM sero-prevalence and any of the studied sociodemographic factors as well as risk factors including abortion, intrauterine death and hypertension ( $\mathrm{p}>0.05)$.

Conclusion: The association was detected between the CMV-specific IgM sero-prevalence and history of abortion and / or intra-uterine death but no significant may be due to small sample size in the present study.

Keywords: Cytomegalovirus,Seroprevalence,Abortion , Kurdistan region

Corresponding Author: katansabir@yahoo.com

Received: $18^{\text {th }}$ August 2019

Accepted: $10^{\text {th }}$ October 2019

DOI:https://doi.org/10.26505/DJM.18014870818

\footnotetext{
${ }^{1}$ Medical Microbiology- Hawler Medical University-Erbil-Iraq.
} 


\section{Introduction}

Cytomegalovirus is a member of the herpesviridae family, it belongs to the subfamily of beta herpes virus that infects a large proportion of the human population[1]. CMV also known as Human Herpesvirus type 5 (HHV-5)[2]. CMV has a genome of $240 \mathrm{~kb}$ and diameter of $200 \mathrm{~nm}$, it contains double-stranded DNA enclosed by an icosahedral capsid. The core is assembled in the nucleus of the host cells. The capsid is surrounded by a poorly defined amorphous tegument in which it is surrounded by lipid containing envelope[3].

This virus, like all of the other herpes viruses, establishes latency and reactivation within the human host[2]. CMV transmission occurs through person-to-person contact $[3,4]$. It can be transmitted trans-placentally to neonates or through breast milk of an infected and shedding mother by intimate contact and by transplantation from (or sharing syringes with) an infected individual[4].CMV infection is in general, clinically mild or silent in immunecompetent hosts, whereas it can lead to severe disease and mortality in immunecompromised patients[5]. CMV is the major causative agent of prenatal and perinatal infections and may lead to important complications of pregnancy[6,7]. CMV infection was a complex phenomenon since the virus act as an immune modulator through elaborating an array of immune evasion strategies to avoid elimination from the host, and its viral proteins an involved in the regulation of cellular gene expression and induction of proinflammatory cytokine or induction of autoimmune status[6].In addition, many factors enhanced the magnitude of HCMV as a health problem such as, no specific antiviral therapy for HCMV infection and no licensed vaccine. 8 Primary infection or reactivation of the previously acquired CMV can occur during pregnancy and can result in congenital CMV; the most important cause of congenital viral infections [9].

The established link between primary CMV infection during pregnancy and congenital infections makes identification of primary CMV infection an important goal in maternal and neonatal health care[10]. The primary infection results in a persistent or latent infection that can be established within various tissues, peripheral blood mononuclear cells and endothelial cells, the only cells that are fully permissive for CMV replication in vitro are human fibroblasts[2,11].

Several studies have demonstrated that CMV is important as it causes abortion and in more cases congenital damage, fetal death and mental retardation[12].Congenital infection results from in utero transmission after maternal primary infection, reinfection,or reactivation of latent infection (i.e. recurrent infection)[13-14-15].These findings suggest that latent genital tract CMV infection predisposes to adverse pregnancy outcomes[16].

Congenital HCMV infection is defined by detection of the virus in the newborn's urine, blood, or saliva within three weeks of birth [17].Typical clinical findings of congenital 
The Sero-Prevalence of Cytomegalovirus Infection among Women with Abortion and Intrauterine Death in

Erbil City Kurdistan Region, Iraq

CMV include intrauterine growth restriction, microcephaly, hepatosplenomegaly, petechiae, jaundice, thrombocytopenia, anemia, chorioretinitis, hearing impairment, and/or other atypical findings $[18,19]$. Cytomegalovirus infection is more widespread in developing countries and in communities with lower socioeconomic status and represents the most significant viral cause of birth defects in industrialized countries. 20 In addition, congenital HCMV may indeed exert its greatest burden on developing countries due to high birth rates and high seroprevalence [8].

The sero-positivity rates varies around the world, ranging from $40 \%$ in developed countries up to $100 \%$ in developing countries.9 Laboratory methods are required to diagnose acute CMV infections since most present with nonspecific symptoms[14]. Diagnosis of primary maternal CMV infection depends on detection of virusspecific immunoglobulin $\mathrm{G}(\operatorname{IgG})$ antibody in the blood of a pregnant woman who was previously sero-negative, or on detection of specific immunoglobulin M (IgM) antibody associated with low $\operatorname{IgG}$ avidity $[7,18]$. $\mathrm{CMV}$-specific immunoglobulin $\mathrm{M}$ ( $\operatorname{IgM})$ is produced during primary infection, but it is also detectable during reactivation and reinfection[21].IgM antibody is present 4 to 8 weeks following the primary infection and can persist for years. Nevertheless, false positive results can occur due to crossreactivity with other diseases, such as autoimmune disorders or other viral infections [7]. The detection of CMV IgM has been used as a marker of active or recent CMV infection. Thus, the simultaneous detection of both CMVIgG and IgM in a screen-naïve pregnant woman may represent a primary infection[22].Therefore, the need of serological evaluation of CMV specific IgM during pregnancy has been supported by various investigators[19].

The IgG antibodies, the only type of antibody that can cross the placenta, provide passive immunization in the fetus throughout the pregnancy. However, the IgG2 subclass antibodies cannot pass through the placenta and merge capsular/polysaccharide antigen which create IgG2 response; therefore, some infections related to these antigens may persist and can lead to serious intrauterine infection[7]. CMV-IgG is an indicator of post or current infection, it remains in the body for a long time and can protect person for the rest of his/her life. IgG seronegativity is a sign of no CMV infection in the past and present. Because of high prevalence of CMV-IgG, it detection has a minimal diagnostic value, but it can be very useful for identification of seronegative people[23].

The objectives of the present study is to find out the sero-prevalence of CMV IgM and $\operatorname{IgG}$ and its association the history of abortion and / or intra-uterine death, as well as, to study the association between the mentioned prevalence with some sociodemographic variables like age, occupation, education, and socio-economic status.

\section{Patients and Methods}

\section{The study design}


The Sero-Prevalence of Cytomegalovirus Infection among Women with Abortion and Intrauterine Death in

Erbil City Kurdistan Region, Iraq

This case-control study was performed during the period from October 2018 to April 2019 in Erbil city (Kurdistan region/Iraq) on 75 pregnant women with history of abnormal pregnancy (history of intra-uterine death and / or abortion) who have been referred by the gynecologists to the central laboratory department of the Maternity Teaching Hospital for detection of CMV specific IgM and IgG markers using immunoassay CMV IgM and IgG kit (Elecsys and Cobas e Analyzar, Roche , Germany).

The control group was composed of 75 pregnant healthy women without history of obstetric problems. The included age range of the women was $18-44$ years. The study was approved by the Ethics Committee of Health Sciences College, Hawler Medical University and an informed consent was obtained from patients and controls. Women with spontaneous abortions due to infectious agents other than the CMV, and women with autoimmune diseases confirmed by laboratory results were excluded from the study.

\section{The blood sample collection}

Five $\mathrm{ml}$ of blood have been withdrawn from each woman of the patients and control groups under aseptic conditions, by venepuncture, using disposable syringes. The blood samples were put in plastic tubes and allowed to clot at $37^{\circ} \mathrm{C}$ for 30 minutes before centrifugation, and then centrifuged at 3000 rpm for 5 minutes for serology test. The serum samples were processed by immunoassay CMV IgM and IgG kit
(Elecsys and Cobas e Analyzar, Roche , Germany) for the detection and evaluation of cytomegalovirus IgM / IgG levels.

\section{The principle of the tests}

The cobas e module is a fully automated analyzer that uses a patented electro chemiluminescence (ECL) technology for immunoassay analysis. The samples are diluted with diluent.

The $1^{\text {st }}$ incubation : the diluted sample is incubated with biotin monoclonal labeled (reagent) with anti human $\operatorname{IgG}$ or $\operatorname{IgM}$ specific antibodies.

The $2^{\text {nd }}$ incubation: the CMV specific recombinant antigen labeled with a ruthenium (reagent) are added to streptavidin-coated micro-particles.

In the presence of anti CMV IgM or anti CMV IgG antibodies in the sample react with the ruthenium-labeled CMV specific recombinant antigen form a sandwich complex. The complex becomes bound to the solid phase via interaction of biotin and streptavidin. The reaction mixture is aspirated into the measuring cell where the microparticles are magnetically captured onto the surface of the electrode. Unbound reagents are then removed out of the system and bound antibody is detected by measuring voltage-induced chemiluminescence emission from the ruthenium labels by a photomultiplier.

Results are determined automatically by the software by comparing the electrochemiluminescence signal obtained from the reaction product of the sample with 
The Sero-Prevalence of Cytomegalovirus Infection among Women with Abortion and Intrauterine Death in

Erbil City Kurdistan Region, Iraq

the signal of the cutoff value previously obtained by calibration.

\section{The procedure}

The micro particles of reagents were resuspended automatically prior to use. The cooled reagents were exposed to approximately $20^{\circ} \mathrm{C}$ and then placed on the reagent disk $\left(20^{\circ} \mathrm{C}\right)$ of the analyzer, the test ${ }^{-}$ specific parameter was read via the reagent barcode. The calibration was performed once per reagent using (CMV IgM calibrator Cal1, CMV IgM calibrator Cal2) and (CMV IgG calibrator Cal1, CMV IgG calibrator Cal2). The serum samples were placed in the sample zone, then automatically read in the analyzer.

The controls for the various concentration ranges was run individually at least once every 24 hours when the test is in use, once per reagent kit, and following each calibration. The CMV specific IgM was calculated automatically by the analyzer, based on the measurement of CMV IgM Cal1 (negative calibrator 1) and CMV IgM Cal2 (positive calibrator 2 ).

Interpretation of the results was obtained with the CMV IgM immunoassay as follows: Non-reactive: < 0.7 COI (cutoff-index), reactive: $\geq 1.0 \mathrm{COI}$. For $\mathrm{CMV}$ specific $\mathrm{IgG}$ calculation, the analyzer automatically calculates the analytic concentration of each sample in $\mathrm{U} / \mathrm{mL}$. Interpretation of the results of CMV IgG assay was as follows: Nonreactive: $<0.5 \mathrm{U} / \mathrm{mL}$, reactive: $\geq 1.0 \mathrm{U} / \mathrm{mL}$

\section{Statistical analysis}

Data were analyzed using the Statistical Package for Social Sciences (SPSS, version 22). Chi square test of association was used to compare proportions. Fisher's exact test was used when the expected count of more than $20 \%$ of the cells of the table was less than 5. A $p$ value of $\leq 0.05$ was considered statistically significant.

\section{Results}

The total number of women was 150 , half of them were women with history of intrauterine death and / or abortion (patients) and the other half were considered as a control group. Their mean age $+\mathrm{SD}$ was $30.24+$ 7.01 years. It is evident in Table 1 that the highest proportion of the women aged $\geq 35$ years, but there was no significant difference in the age distribution of the two study groups $(\mathrm{p}=0.272)$.

The majority of the patients $(80 \%)$ had history of abortion, and $37.3 \%$ had history of intrauterine death, while none of the control group had such a history ( $p<0.001)$ as presented in Table (1) which shows also that the prevalence of hypertension was $12.7 \%$ in the whole sample but the difference was not significant between the study groups ( $\mathrm{p}=$ 0.806). 
The Sero-Prevalence of Cytomegalovirus Infection among Women with Abortion and Intrauterine Death in

Table (1): The basic characteristic of the two study groups

\begin{tabular}{|c|c|c|c|c|c|c|c|}
\hline & \multicolumn{2}{|c|}{ Control } & \multicolumn{2}{|c|}{ Patients } & \multicolumn{2}{|c|}{ Total } & \multirow[b]{2}{*}{$\mathrm{p}$} \\
\hline & No. & $(\%)$ & No. & $(\%)$ & No. & $(\%)$ & \\
\hline Age & & & & & & & \\
\hline$<25$ & 22 & (29.3) & 12 & (16) & 34 & (22.7) & \\
\hline $25-29$ & 17 & (22.7) & 21 & (28) & 38 & (25.3) & \\
\hline $30-34$ & 16 & (21.3) & 20 & (26.7) & 36 & (24) & \\
\hline $\begin{array}{l}\geq 35 \\
\text { Abortio }\end{array}$ & 20 & (26.7) & 22 & (29.3) & 42 & (28) & 0.272 \\
\hline No & 75 & (100.0) & 15 & $(20.0)$ & 90 & $(60.0)$ & \\
\hline Yes & $\overline{0}$ & $\begin{array}{l}(0.0) \\
\end{array}$ & 60 & $\begin{array}{l}(80.0) \\
\end{array}$ & 260 & $\overline{(40.0)}$ & $<0.001$ \\
\hline \multicolumn{8}{|c|}{ Intrauterine death } \\
\hline No & 75 & (100.0) & 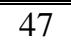 & $\overline{~(62.7)}$ & 122 & $\begin{array}{l}(81.3) \\
\end{array}$ & \\
\hline Yes & 0 & $(0.0)$ & 28 & (37.3) & 28 & (18.7) & $<0.001$ \\
\hline \multicolumn{8}{|c|}{ Hypertension } \\
\hline No & 66 & $(88.0)$ & 65 & $(86.7)$ & 131 & $(87.3)$ & \\
\hline Yes & 9 & $\begin{array}{l}(12.0) \\
\end{array}$ & 10 & $\begin{array}{l}(13.3) \\
\end{array}$ & 19 & $\begin{array}{l}(12.7) \\
\end{array}$ & 0.806 \\
\hline Total & 75 & (100.0) & 75 & (100.0) & 150 & (100.0) & \\
\hline
\end{tabular}

Figure (1) shows that $8 \%$ of the patients were Results showed that all the patients and reactive to $\mathrm{IgM}$ while none of the control controls were reactive to $\mathrm{IgG}$. group were reactive to $\operatorname{IgM}(\mathrm{p}=0.028)$.

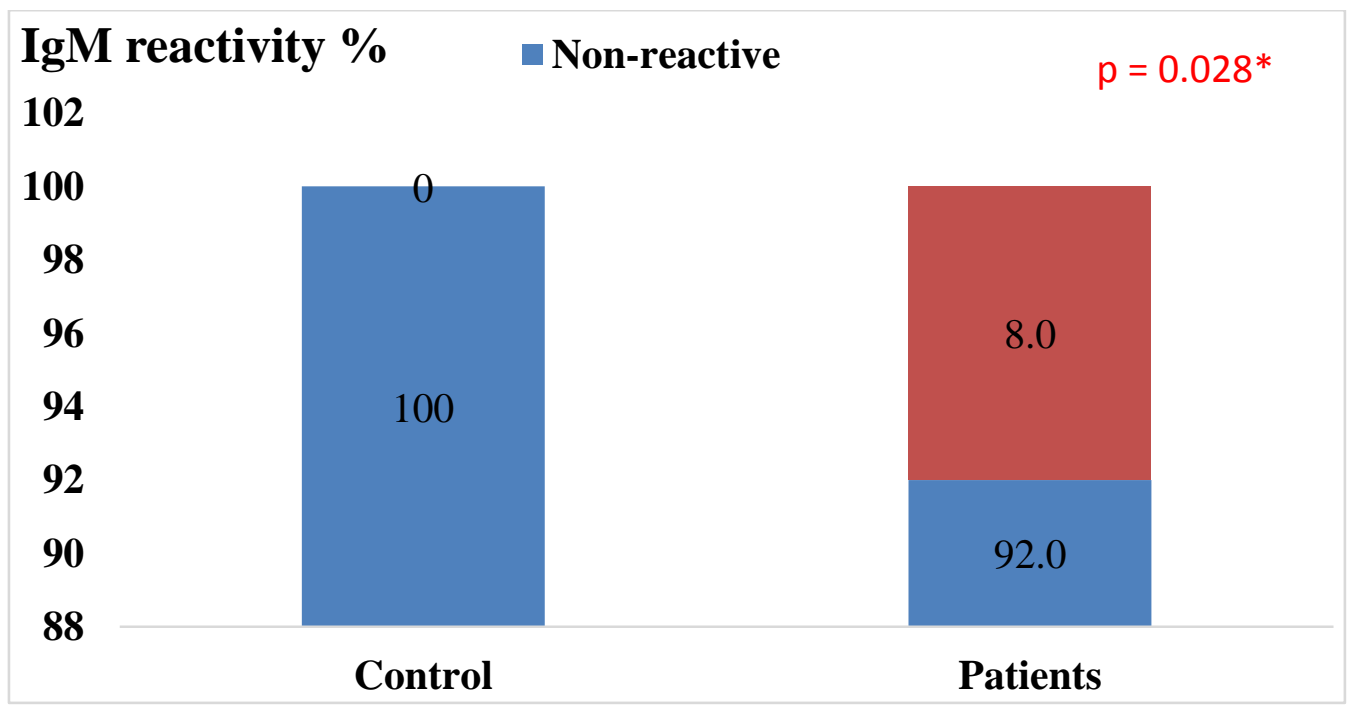

Figure (1): IgM reactivity among patients of the two study groups

*By Fisher's exact test. Note: All the patients and controls were reactive to IgG 
The Sero-Prevalence of Cytomegalovirus Infection among Women with Abortion and Intrauterine Death in

Erbil City Kurdistan Region, Iraq

As mentioned before, the IgM reactivity among the patients was $8 \%$. Table 2 shows that the $\operatorname{IgM}$ reactivity was $16.7 \%$ among women aged less than 25 years, but the differences were not significant $(\mathrm{p}=0.684)$. None of the college graduates had reactive $\operatorname{IgM}$, while $12.5 \%$ of the primary schools graduates were reactive to $\operatorname{IgM}(\mathrm{p}=0.545)$. The same table shows also that there was no significant association between IgM reactivity and other factors like occupation ( $\mathrm{p}$ $=0.327)$, and socio-economic status ( $\mathrm{p}$ $>0.999$ ).

Table (2): Ig M reactivity by socio-demographic characteristics among cases

\begin{tabular}{|c|c|c|c|c|c|c|c|}
\hline & \multicolumn{2}{|c|}{ Non-reactive IgM } & \multicolumn{2}{|c|}{ Reactive IgM } & \multicolumn{2}{|c|}{ Total } & \multirow[b]{2}{*}{$\mathrm{p}$} \\
\hline & No. & $(\%)$ & No. & $(\%)$ & No. & $(\%)$ & \\
\hline \multicolumn{8}{|l|}{ Age } \\
\hline$<25$ & 10 & (83.3) & 2 & (16.7) & 12 & $\begin{array}{l}(100.0) \\
\end{array}$ & \\
\hline $25-29$ & 20 & $(95.2)$ & 1 & $(4.8)$ & 21 & $(100.0)$ & \\
\hline $30-34$ & 19 & $(95.0)$ & 1 & $(5.0)$ & 20 & $(100.0)$ & \\
\hline$\geq 35$ & 20 & $(90.9)$ & 2 & $(9.1)$ & 22 & (100.0) & $0.684 *$ \\
\hline \multicolumn{8}{|c|}{ Educational level } \\
\hline Illiterate & 11 & (91.7) & 1 & $(8.3)$ & 12 & $(100.0)$ & \\
\hline Primary & 21 & $(87.5)$ & 3 & $(12.5)$ & 24 & $(100.0)$ & \\
\hline Secondary & 20 & $(90.9)$ & 2 & $(9.1)$ & 22 & $(100.0)$ & \\
\hline College & 17 & $(100.0)$ & 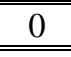 & 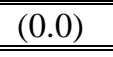 & 17 & $\begin{array}{l}(100.0) \\
\end{array}$ & $0.545^{*}$ \\
\hline \multicolumn{8}{|l|}{ Occupation } \\
\hline Housewife & 52 & $(89.7)$ & 6 & $(10.3)$ & 58 & $(100.0)$ & \\
\hline Employed & 17 & $(100.0)$ & 0 & $(0.0)$ & 17 & $(100.0)$ & $0.327 *$ \\
\hline \multicolumn{8}{|c|}{ Socio-economic status } \\
\hline Low & 26 & $(92.9)$ & 2 & $(7.1)$ & 28 & $(100.0)$ & \\
\hline Medium & 43 & $(91.5)$ & 4 & $(8.5)$ & 47 & $(100.0)$ & $>0.999 *$ \\
\hline Total & 69 & $(92.0)$ & 6 & $(8.0)$ & 75 & $(100.0)$ & \\
\hline
\end{tabular}

*By Fisher's exact test

No significant association was detected between $\operatorname{IgM}$ reactivity with history of abortion ( $\mathrm{p}>0.999$ ), recurrent abortion $(\mathrm{p}$ $>0.999)$, intrauterine death $(\mathrm{p}>0.999)$, intrauterine death number $(\mathrm{p}>0.999)$, and hypertension $(\mathrm{p}>0.999)$ as presented in Table (3). 
The Sero-Prevalence of Cytomegalovirus Infection among Women with Abortion and Intrauterine Death in

Table (3): Ig M reactivity by abortion, intra uterine death and hypertension among cases

\begin{tabular}{|c|c|c|c|c|c|c|c|}
\hline & \multicolumn{2}{|c|}{ Non-reactive IgM } & \multicolumn{2}{|c|}{ Reactive IgM } & \multicolumn{2}{|c|}{ Total } & \multirow[b]{2}{*}{$\mathrm{p}$} \\
\hline & No. & $(\%)$ & No. & $(\%)$ & No. & $(\%)$ & \\
\hline \multicolumn{8}{|l|}{ Abortion } \\
\hline No & 14 & (93.3) & 1 & $(6.7)$ & 15 & $(100.0)$ & \\
\hline Yes & 55 & (91.7) & 5 & (8.3) & 60 & (100.0) & $>0.999 *$ \\
\hline Total & 69 & $(92.0)$ & 6 & $(8.0)$ & 75 & (100.0) & \\
\hline \multicolumn{8}{|c|}{ Recurrent abortion } \\
\hline Primary & 36 & $(92.3)$ & 3 & (7.7) & 39 & $(100.0)$ & \\
\hline Recurrent & 19 & $(90.5)$ & 2 & (9.5) & 21 & (100.0) & $>0.999 *$ \\
\hline Total & 55 & (91.7) & 5 & $(8.3)$ & 60 & $(100.0)$ & \\
\hline \multicolumn{8}{|c|}{ Intrauterine death } \\
\hline No & 43 & (91.5) & 4 & $(8.5)$ & 47 & (100.0) & \\
\hline Yes & 26 & (92.9) & 2 & $(7.1)$ & 28 & $(100.0)$ & $>0.999 *$ \\
\hline Total & 69 & (92.0) & 6 & $(8.0)$ & 75 & $(100.0)$ & \\
\hline \multicolumn{8}{|c|}{ IUD number } \\
\hline One & 22 & $(91.7)$ & 2 & $(8.3)$ & 24 & $(100.0)$ & \\
\hline Two & 3 & $(100.0)$ & 0 & $(0.0)$ & 3 & (100.0) & $>0.999^{*}$ \\
\hline Total & 25 & (92.6) & 2 & (7.4) & 27 & $(100.0)$ & \\
\hline \multicolumn{8}{|c|}{ Hypertension } \\
\hline No & 59 & $(90.8)$ & 6 & $(9.2)$ & 65 & $(100.0)$ & \\
\hline Yes & 10 & $(100.0)$ & 0 & $(0.0)$ & 10 & $(100.0)$ & $>0.999 *$ \\
\hline Total & 69 & $(92.0)$ & 6 & $(8.0)$ & 75 & $(100.0)$ & \\
\hline
\end{tabular}

*By Fisher's exact test.

\section{Discussion}

CMV is endemic in all parts of the world, while epidemics are unknown. It is present throughout the year, with no seasonal variation seen in infection rates, the prevalence of infection varies with socioeconomic status, living conditions, and hygiene practices[8]. The present study showed that all the women, whether cases or controls, showed a positive CMV IgG. This rate is considered to be higher than the rates reported in Iraqi studies, Baghdad (85\%)[2] Al- Diwaniyah (54\%)[24], Waset
(55\% ) [25] Babylon, (77.8\%) [26] but it is nearly similar to what was reported in other studies like Turkey $(97.9 \%)$ [7]. India (97\%),[3] Kirkuk province, Iraq (92.1\%)[6], Nijerya (92\%), [27] and Khorramabad, Iran (90.6\%)[23]. These discrepancies, could be attributed to the differences in the sensitivity and specificity of the serologic markers were used in these studies from other provinces of Iraq in comparison to present study and the differences in the sample size. It has been concluded that the development of $\mathrm{IgG}$ 
The Sero-Prevalence of Cytomegalovirus Infection among Women with Abortion and Intrauterine Death in

Erbil City Kurdistan Region, Iraq

antibodies to CMV indicates that these women had been previously infected with the CMV in their life time[20] and the high levels of sero-positivity of CMV may be due to the vertical transmission of the virus from the mother to the fetus or from the mother to the newborn[3]. The high sero-prevalence could be attributed also to the wide practice of breastfeeding during infancy in $\operatorname{Iraq}[6,20]$ as breast feeding is one of the main routes of transmission of CMV[17]Additionally, in a high sero-prevalence population, a pregnant woman has a higher likelihood of exposure to CMV-infected people[6]. Also, another study from province Bagdad, Iraq[20], reported that the high positive results for IgG could be attributable to the majority of women of childbearing age are seropositive for HCMV and that they contract the infection either through prenatal or postnatal transmission during early childhood.

The CMV IgM sero-positive rate was $8 \%$ among women with abnormal pregnancy and was $0 \%$ in healthy women. The seroprevalence of CMV $\operatorname{IgM}$ in this study is lower than what was reported in Iraqi studies, Waset (60.2\%) [25] Babylon (57.2\%) [26]Al- Diwaniyah (16\%)[24] and Baghdad, Iraq $(15.7 \%$ and 10\%)[28,2] However, it was higher than the rates that have been documented by other studies (7.2\% in Malysia [29] $2.1 \%$ in Turkey[7] $4 \%$ in Nijerya[27] and $3.8 \%$ in Kirkuk, Iraq[6 ].

Even if the sero-prevalence of CMV IgM is low among pregnant women, but it should be considered seriously as the risk of congenital
CMV infection is much higher during primary maternal infection[30].

Furthermore, the diagnosis of acute CMV infection in pregnancy is based on positive results for maternal IgM[2]. In addition, a negative IgM result does not necessarily rule out a primary infection with CMV as samples collected too early in the course of a primary infection may not have detectable levels of IgM and it may reappear during reactivation of CMV[27]. On the other hand, the low prevalence of CMV specific $\operatorname{IgM}$ is possibly due to the fact that the majority of the women would have recovered from the primary in $\neg$ fection, with the loss of IgM, by the time they reach child bearing age 30 Primary CMV infection was identified as sero-conversion in previously CMV seronegative women or by detection of CMVspecific IgM combined with low avidity antiCMV IgG [31]. Moreover, the pre conception immunity against CMV provides only partial protection from intrauterine transmission of the virus[18]. A study reported that the cause of transmission of the virus from mothers, who were CMV sero-positive before conception, to their offspring could be due to infection with a new strain of CMV[7] While, another study reported that, in pregnant women, recurrent infections are always asymptomatic and are primarily caused by the reactivation of the endogenous virus, rather than by a low-grade chronic infection or by re-infection by a different strain of CMV[8,22 ]. As well as, it has been reported that the presence of anti-CMV IgM antibody represents the acute state of CMV 
The Sero-Prevalence of Cytomegalovirus Infection among Women with Abortion and Intrauterine Death in

Erbil City Kurdistan Region, Iraq

(primary infection) or reactivations of latent infection, where those patients were also positive for anti-CMV (IgG) antibody in the same time which represents previous infection[24].

The rate of CMV IgM sero-positivity according to age showed a statistically nonsignificant difference, but this rate was high (16.7\%) among women aged less than 25 years old. This finding is consistent with the results of a studies that had been done in Baghdad and Al-Diwaniyah, Iraq which showed that the CMV sero-prevalence rate were $17 \%, 16 \%$ among women aged 16-20 and 20-25 years old respectively[2. 24] .Other studies showed also that the prevalence was higher among young women, but the association was not significant with age[20, 23, 27]. The variation in CMV transmission in different age groups could be due to fact that women interaction with the risk factors tend to increase or decrease according to age[6].

Further, in relation to education levels, the study showed that the highest seroprevalence rate of CMV- was among women with primary school level (12.5\%) and none of the women with higher educational level showed sero-positivity for CMV IgM. It has been found also that illiteracy and low education levels were observed as risk factors for increased susceptibility of women to acquisition of CMV infection, perhaps through the direct contact with contagious secretions from their own children and poor hygiene practiced by these women[28]. Regarding the socioeconomic status, in the present study the majority of the women were those of low to middle socioeconomic status. Accordingly, the highest CMV-IgM sero-prevalence was found among women of low and medium socioeconomic status (7.1 $\%$, and $8.5 \%$ respectively) and was not found among women with high socioeconomic status. It has been reported that low socioeconomic status, such a poor living conditions, low household income and poor hygienic practices facilitates independently the CMV transmission by many routes (sexual and non-sexual routes) [1 ,20, 27]. In addition, the relation between the employment status and rate of CMV-IgM seropositivity showed that the high rate of CMV-IgM seropositivity was $10.3 \%$ among housewives as compared to employed women $(0 \%)$. Similar findings were obtained from another study[23] which revealed that pregnant women who were skilled workers were least likely to have CMV infection naturally, Also, it has been suggested that there are likely more sero-negative women among those with higher educational background (especially tertiary education), due to better hygiene compared to those with lower social class and educational background, making the former more susceptible to CMV primary infection[23, 30]. So the results of our study are similar to the findings of the above mentioned studies which found that the high rate of CMV sero-positivity was not significantly associated with the sociodemographic characteristics including: socio-economic 
The Sero-Prevalence of Cytomegalovirus Infection among Women with Abortion and Intrauterine Death in

Erbil City Kurdistan Region, Iraq

status, education levels and employment status.

Results showed that the CMV seroprevalence was $9.5 \%$ in women with repeated abortion as compared to women with primary abortion (7.7 \%), while CMV $\operatorname{IgM}$ sero-prevalence was higher $(8.5 \%)$ in women without intrauterine death as compared to those with intrauterine death $(8.3 \%)$ with non-significant differences .These findings are in agreement with the results of another study[23] which revealed that there was no significant relationship between CMV sero-positivity and history of abortion, while, they disagree with the results of another study[32] which found that the CMV IgM was (16.37\%) among women with repeated abortion and ( 28.85 $\%$ in women with intrauterine death with significant differences. Other studies also reported a significant association between recurrent abortion, premature delivery and intra uterine death and CMV infections causing death of the fetus[25]. Therefore, studies with large samples are required to determine the significant association between CMV sero-prevalence and abortion and intrauterine death .

Finally, the possible association between CMV IgM sero-prevalence and hypertension has also been reported, where none of the women with hypertension was CMV IgM sero-positive. This is in agreement with another study that reported no significant association between CMV IgM and preeclampsia[33].The preeclampsia is a pregnancy-specific disease characterized by high blood pressure which involve impaired placentation and an associated increase in systemic inflammation [33,34]. Other studies, found that the relationship between active maternal CMV infection and preeclampsia, whether this relationship is causal or casual remains to be determined by further studies[22].

\section{Conclusions}

The sero-prevalence of $\operatorname{IgG}$ was $100 \%$ among the studied samples and controls, therefore, screening all the women in childbearing age is recommended due to the possibility of reactivation of the CMV. Other tests are recommended like CMV specific $\operatorname{IgM}$ as the positive $\operatorname{IgM}$ result in combination with a low avidity index for $\operatorname{IgG}$ is a strong indication of a primary CMV infection.

\section{Conflicts of interest}

The authors declare no conflicts of interest.

\section{References}

[1]Bate SL, Dollard SC, Cannon MJ. Cytomegalovirus Seroprevalence in the United States: The National Health and Nutrition Examination Surveys, 1988- 2004. Clinical infectious diseases. 2010;50(11):1439-47.

[2]Al-Baiati AM, Muhsin MA, Jabbar RN. Seroprevalence Of Human Cytomegalovirus (HCMV) in Aborted Women in Baghdad. International Journal of Current Microbiology and Applied Sciences. 2014;3(2):97-102.

[3]Ram MR, Syam DG. Seroprevalence Of Cytomegalovirus In Antenatal Cases With 
The Sero-Prevalence of Cytomegalovirus Infection among Women with Abortion and Intrauterine Death in

Erbil City Kurdistan Region, Iraq

Bad Obstetric History At Warangal,

Telangana, Indi

Int.J.Curr.Microbiol.App.Sci. 2015 ; 4(11): 422-430.

[4]Stockdale L, Nash S, Nalwoga A, Painter H, Asiki G, Fletcher H, Robert Newton R. Human Cytomegalovirus Epidemiology and Relationship to Tuberculosis And Cardiovascular Disease Risk Factors in a Rural Ugandan Cohort. PLOS ONE | Https://Doi.Org/10.1371/Journal.Pone.01920

86. 2018: 1-16.

[5]Lilleri D, Fornara C, Revello MG, Gerna G. Human cytomegalovirus-specific memory CD8+ and CD4+ $\mathrm{T}$ cell differentiation after primary infection. The Journal of infectious diseases. 2008 15;198(4):536-43.

[6]Hassan HM, Alsamarai AM, Mohamed ZK, Aljumaili AH. Association Between Cytomegalovirus Infection and $\mathrm{Bad}$ Obstetric Outcomes in Women from Kirkuk. International Journal of Public Health. 2014;3(1):29-42.

[7]Usta A, Taskin MI, Usta CS, Dalkiran ES, Kilinc O, Dus E. Screening Cytomegalovirus Infections in

First Trimester of Gestation among High Prevalence Population. Acta Medica Anatoli. 2016 : 1(4):101-6.

[8]Alwan SN , Al-Saffar AJ , Bayati AH, Kadhim HS, et al . Prevalence of Cytomegalovirus in Iraqi Children. Int J Med Res Health Sci 2017: 6 (11): 113-124. [9]Sherkat R, Meidani M, Zarabian H, Rezaei A, Gholamrezaei A. Seropositivity of Cytomegalovirus in Patients With
Recurrent Pregnancy Loss. Journal of Research in Medical Sciences: 2014;19 (Suppl1):S22-25.

[10]Prince HE, Lapé-Nixon M. Role of Cytomegalovirus (CMV) IgG Avidity Testing in Diagnosing. Primary CMV Infection During Pregnancy. Clin. Vaccine Immunol..2014;21(10):1377-84.

[11]Revello MG, Gerna G. Diagnosis and Management of Human Cytomegalovirus Infection in the Mother, Fetus, and Newborn Infant. Clinical Microbiology Reviews. 2002;15(4):680- 715.

[12]Sana AAW .Cytomegalovirus Incidence in Pregnant Women With Recurrent Abortion. J Bioanal. Biomed.2012;4 (6 ):103101.

[13]Guibert G, Warszawski J, Le Chenadec J, Blanche S, Benmebarek Y, Mandelbrot L, Tubiana R ‘Rouzioux C, Leruez-Ville M, Cohort FP. Decreased Risk of Congenital Cytomegalovirus. Infection in Children Born to HIV-1-Infected Mothers in the Era of Highly Active Antiretroviral Therapy. Clinical Infectious Diseases. 2009 ;48(11):1516-25.

[14]Munro SC, Hall B, Whybin LR, Leader L, Robertson P, Maine GT, Rawlinson WD. Diagnosis of and Screening for Cytomegalovirus Infection in Pregnant Women. Journal of Clinical Microbiology. 2005 ;43(9):4713-8.

[15]Manicklal S, Emery VC, Lazzarotto T, Boppana SB, Gupta RK. The "Silent" Global Burden of Congenital Cytomegalovirus. Clinical Microbiology Reviews. 2013; 26(1):86-102. 
The Sero-Prevalence of Cytomegalovirus Infection among Women with Abortion and Intrauterine Death in

Erbil City Kurdistan Region, Iraq

[16] Nigro G, Mazzocco M, Mattia E, Di Renzo GC, Carta G, Anceschi MM. Role of the Infections in Recurrent Spontaneous Abortion. The Journal Of Maternal-Fetal \& Neonatal Medicine. 2011;24(8):983-9.

[17]Blaho JA. Human Cytomegalovirus Infection In Pregnant Women And Neonates: A New Risk. Factor for Cardiovascular Disease?. Archives of Clinical Microbiology. 2010 ;1(1) 5.

[18]Ornoy A. Fetal Effects Of Primary and Non-Primary Cytomegalovirus Infection in Pregnancy: are We Close to Prevention?. IMAJ-RAMAT GAN-. 2007 ;9(5):398-401. [19]Dawood AL-Taie AA . Serological Study for TORCH Infections in Women with High Delivery Risk Factors in Mosul. Tikrit Journal of Pure Science. 2010: 15 (1) :1813 1662.

[20]Hameed MY, Aziz IH. Detection of Cytomegalovirus in Iraqi Recurrent Miscarriage Women. Journal of Pharmacy and Pharmaceutical Sciences. 2015;5(1):7989.

[21]Lagrou K, Bodéus M, Van Ranst M, Goubau P. Evaluation of The New Architect Cytomegalovirus Immunoglobulin $\mathrm{M}$ (IgM), IgG, And IgG Avidity Assays. Journal of Clinical Microbiology. 2009 ;47(6):16959.

[22]Olumuyiwa AJ, Christianah OA, Daisi AD, Olabisi AA. Socio-biologic Predictors of Active Cytomegalovirus Infection Among Pregnant Women in a Low-resource Setting. Journal of Gynecology and Obstetrics. 2019 ;7(1):25-30.
[23] Delfan-Beiranvand M, Sheikhian A, Birjandi M, Fazeli M. Seroprevalence of Cytomegalovirus Infection in Pregnant Women Referred to Health Care Center of Khorramabad. Iranian Journal of Virology. 2011;5(4):11-16.

[24]Maani N. Al-Shimmery MN, Al-Hilaly HA and AI-khafaji AA. Seroprevalence of Cytomegalovirus and Toxoplasmosis In Cases Of Miscarriages Women In AlDiwaniyah Province. OMJ. 7(11):160- 168. [25]Jasim M, Majeed HA, Ali AI. Performance of Serological Diagnosis Of TORCH Against in Aborted Versus Non Aborted Women of Waset Province in Iraq. Tikrit Medical Journal. 2011; 17(2): 141147.

[26]Marzoqi AHM. Kadhim RA, Al-Janabi DKF, Hussein HJ, Al Taee ZM. Seroprevalence Study of IgG and IgM Antibodies to Toxoplasma, Rubella, Cytomegalovirus, Chlamydia Trachomatis and Herpes Simplex II in Pregnancy Women in Babylon Province. Journal of Biology, Agriculture and Healthcare.2012; 2(10) :159-164.

[27]Ogbaini-Emovon E, Oduyebo OO, Lofor PV, Onakewhor JU, Elikwu CJ. Seroprevalence and Risk Factors for Cytomegalovirus Infection among Pregnant Women in Southern Nigeria. Journal of Microbiology and Infectious Diseases. 2013 ;3 (03):123-7.

[28]Khalf MS. The seroprevalence of IgM among Iraqi aborted women infected with human Cytomegalovirus. Iraqi Academic Scientific Journal. 2012;11(1):123-9. 
The Sero-Prevalence of Cytomegalovirus Infection among Women with Abortion and Intrauterine Death in

Erbil City Kurdistan Region, Iraq

[29]Saraswathy TS, Az-Ulhusna A, Asshikin RN, Suriani S, Zainah S. Seroprevalence of Cytomegalovirus Infection in Pregnant Women and Associated Role in Obstetric Complications: A Preliminary Study. Southeast Asian J Trop Med Public Health . 2011; 42 ( 2 ): 320-322.

[30]Babayo A, Yunusa T, Abdullahi Nasir I, Baba MB. Serological Evidence And Sociodemographic Risk Factors Of Recent Cytomegalovirus Infection In Pregnant Women Attending A Tertiary Hospital in Maiduguri, Nigeria. Journal of Medical Microbiology and Infectious Diseases. 2014;2(2):49-55

[31]Simonazzi G, Curti A, Murano P, Cervi F, Contoli M, Lazzarotto T, Capretti MG, Rizzo N, Guerra B. Congenital Cytomegalovirus Infection and Small for Gestational Age Infants. Prenatal Diagnosis. $2014 ; 34(8): 765-9$.

[32]Rubina lone,; Bashir A. Fomda,; Manzoor Thokar,; Tehmeena Wani,; Dalip Kakru,; Rubina Shaheen,; Asifa Nazir, Seroprevalence of Cytomegalovirus (Cmv) in Kashmir Valley - A Preliminary Study. JKPractitioner. 2004: 11(4) : 261-262. [33]Geraili Z, Riahi SM, Khani S, Et Al. Cytomegalovirus Infection and Risk of Preeclampsia: A Meta-analysis of Observational Studies .Caspian J Intern Med 2018; 9(3): 211-219.

[34]Rădulescu C, Huţanu A, Gabor R, Şincu N. Cytomegalovirus Infection and Preeclampsia. Acta Medica Marisiensis. 2016 ;62 (2):280-84. 